https://doi.org/10.5800/GT-2017-8-3-0285

\title{
GEOCHEMICAL AND CLAY-MINERAL STUDY OF HEALING MUD FROM WUDALIANCHI, NE CHINA
}

\author{
Sergei Rasskazovi, 2, Zhenhua Xie ${ }^{3}$, Tatiana Yasnygina', Irina Chuvashova ${ }^{1,2}$, \\ Xiying Wang33, Kirill Arsentev ${ }^{4}$, Yi-min Sun ${ }^{3}$, Zhenxing Fang3, Ying Zeng3 \\ ${ }^{1}$ Institute of the Earth's Crust, Siberian Branch of RAS, Irkutsk, Russia \\ ${ }^{2}$ Irkutsk State University, Irkutsk, Russia \\ ${ }^{3}$ Institute of Volcano and Mineral Spring, Heilongjiang Academy of Science, \\ Wudalianchi, Heilongjiang 164155, China \\ ${ }^{4}$ Limnological Institute, Siberian Branch of RAS, Irkutsk, Russia
}

Over the centuries, people have used healing mud (peloids) to draw toxins out of the body, boost the immune system, cure psoriasis, acne, depression, and hair loss. The beauty industry has used mud-clay masks, body wraps, soaps, and baths. The useful properties of mud were established empirically. The most popular healing-mud spars are known in the Dead Sea in Israel, Baden-Baden in Germany, Calistoga in California, Budapest in Hungary, Akhtala and Kumisi in Georgia, Paratunka in Kamchatka, Wudalianchi in China.

A healing mud origin is due to a complex combination of geological, hydrological, climatic, physic-chemi- cal, and biological factors. Of particular interest are peloids, the formation of which is associated with the activity of mineral and thermal springs in areas of active volcanism. The healing properties of peloids are due to the presence of microorganisms in them [Stupnikova, Muradov, 2005; Bokuchava, 2009] Peloid properties might depend on whether they contain the usual products of exogenous distraction of the basement rocks or specific products of volcanic activity. Are peloids formed due to the accumulation and transformation of tiny clay material solely due to the destruction of the basement rocks? Does volcanic ash material fall into the mud layers? 
The Wudalianchi healing mud occurs on a volcanic field active over the last $2.5 \mathrm{Ma}$. To identify the likely volcanic specificity of the peloids, we sampled material of 1) these formations in different parts of the field, 2) the present-day soil, and 3) clays from strata underlying the volcanic rocks in two sections. One stratum was exposed by several road pits under the Laoshantou lava flow, which spewed out in the southwestern part of the field at the very beginning of volcanic activity, about 2.5 Ma. The lower part of the stratum exhibits gray, the upper part - brick-red and dark-brown clays. Another stratum was exposed in a quarry of the Forest Farm, located in the northwestern part of the volcanic area. Both stratum are composed of material deposited prior to the onset of the Quaternary volcanism.

Major oxides were measured at the Institute of the Earth's Crust of the SB RAS by "wet chemistry" (analysts: G.V. Bondareva and M.M. Samoilenko) and trace elements by the ICP-MS analysis using the Agilent 7500ce mass-spectrometer (sample preparation of M.E. Markova, measurements of A.P. Chebykin). The method is described by Rasskazov et al. [2016]. Clayfraction compositions were studied using a scanning electron microscope with energy-dispersive X-ray spectroscopy (SEM-EDS) Quanta 200, FEI Company (analyst K.Yu. Arsentev). The both devices were used as the equipment of the Center for Collective Use "Ultramicroanalysis", Limnological Institute of the SB RAS.

Comparison of peloids, modern soil and prevolcanic clays. The $\mathrm{SiO}_{2}$ contents in Wudalianchi peloids (61-64 wt. \%) are higher than in volcanic rocks from this territory (48-55 wt. \%). The contents of $\mathrm{Na}_{2} \mathrm{O}+\mathrm{K}_{2} \mathrm{O}$ in peloids (3.4-4.6 wt. \%) are, on the contrary, lower than in volcanic rocks (6-10 wt. \%). Different type healing mud from Brazil, Turkey, Georgia, and Argentina show $\mathrm{SiO}_{2}$ contents decreasing from this oxide values in the Wudalianchi peloids to $16 \mathrm{wt}$. \% with a minimum content of $\mathrm{Na}_{2} \mathrm{O}+\mathrm{K}_{2} \mathrm{O}(0.55$ wt. \%). This trend is accompanied by increasing sulfur concentrations. No sulphides are found in the Wudalianchi peloids.

Variations of trace-element concentrations in the Wudalianchi peloids were processed using the factor analysis procedure by the method of principal components. In the coordinates of factors 1 and 2, the main weight of the positive values of the variables of the factor 1 (Fig. 1, b) yield rare earth elements (REE) of the

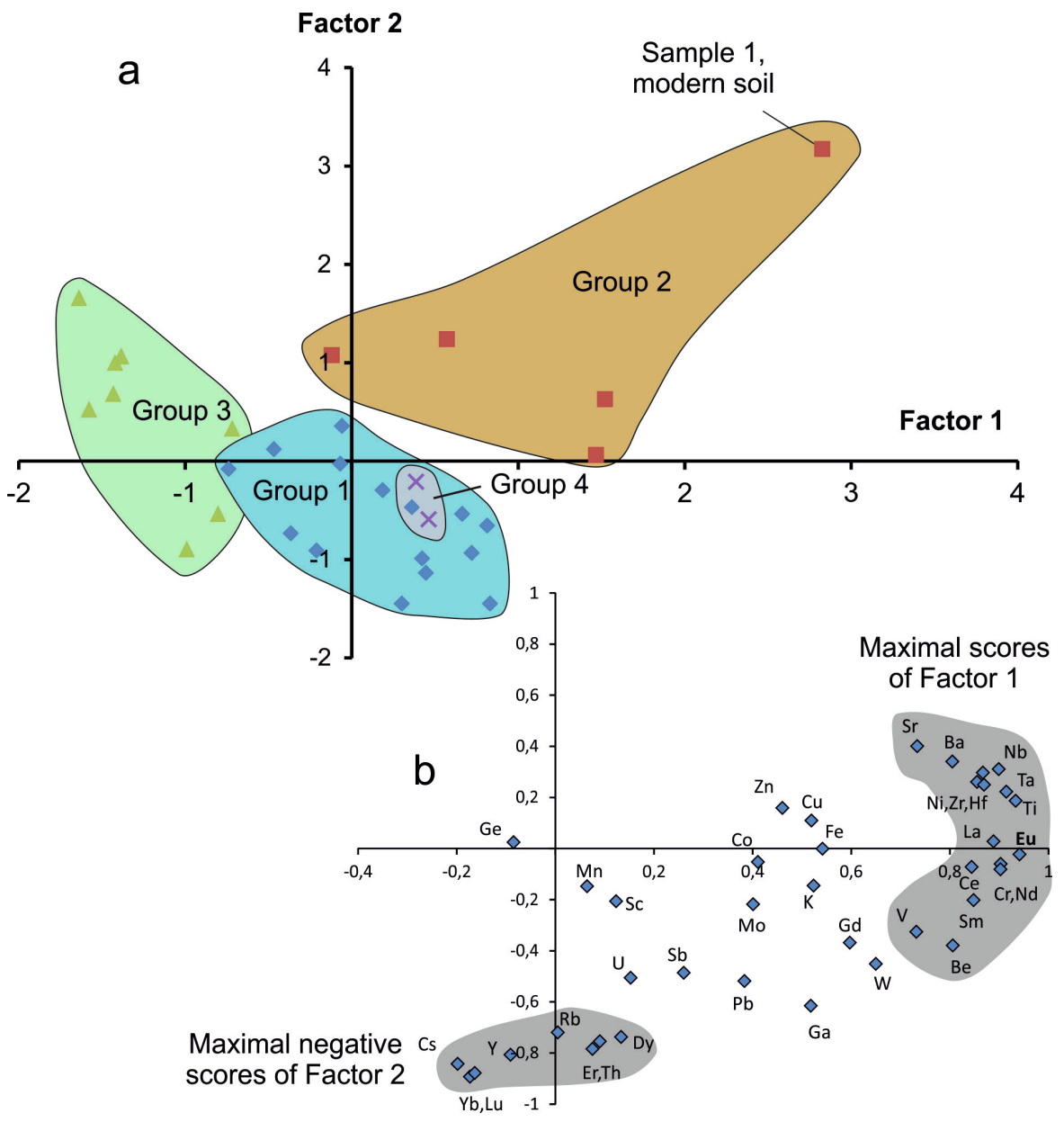

Fig. 1. Diagrams of factors 1 and 2 of the Wudalianchi peloids. $a$-grouping of samples (see text); $b$-grouping of variables (factor scores). 

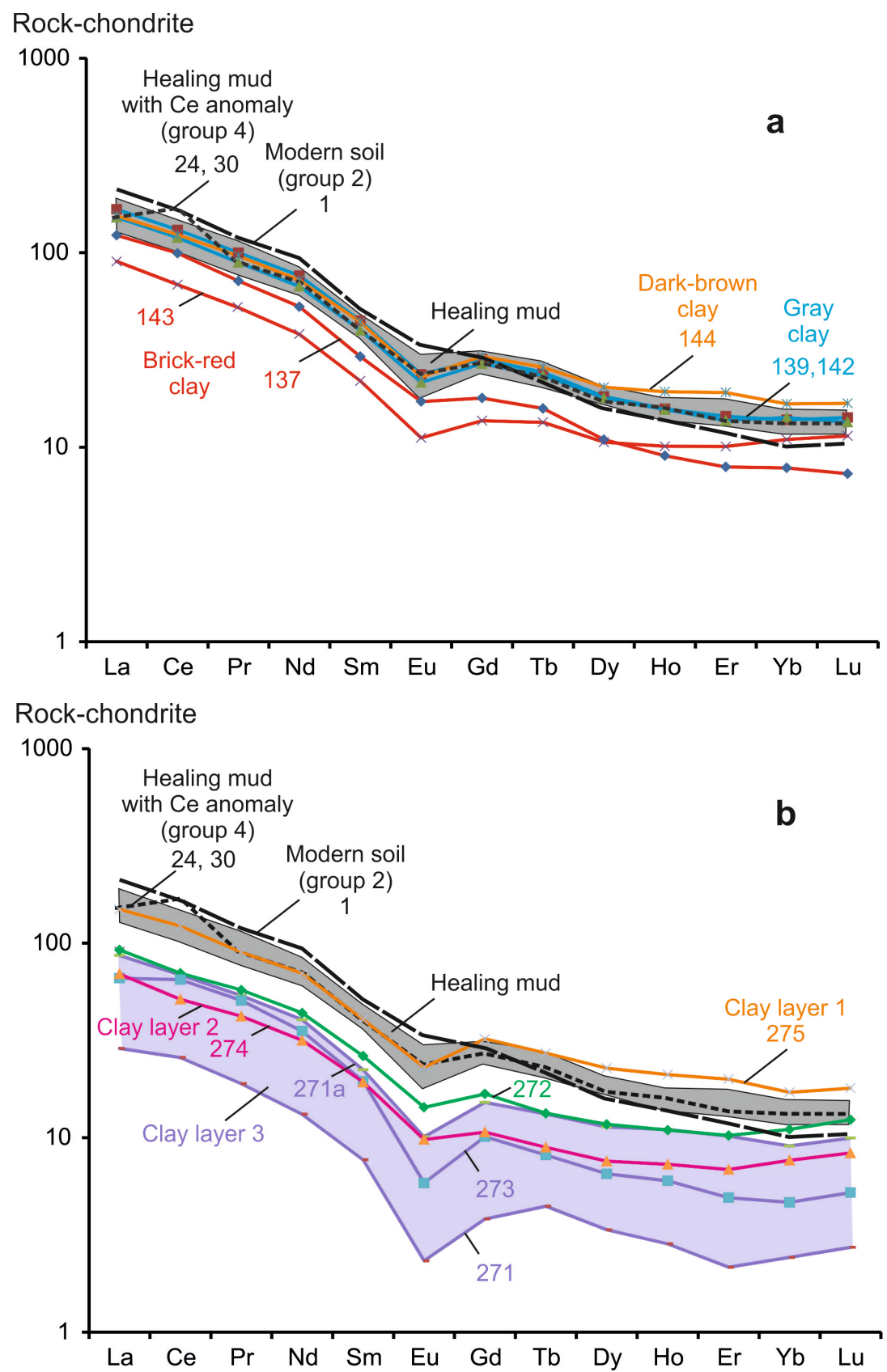

Fig. 2. Comparison of the Wudalianchi peloids, modern soil and pre-volcanic clays from Laoshantou $(a)$ and Wood Farm $(b)$ in the REE diagram normalized to chondrites. The normalizing values of chondrite are after [McDonough, Sun, 1995].

light and middle parts of the series (from La to $\mathrm{Eu}$ ), alkaline earth elements $(\mathrm{Ba}, \mathrm{Sr})$, high-field strength elements (HFSE - Nb, Ta, Zr, Hf, Ti), elements, which are characteristic for rocks of ultrabasic-basic $(\mathrm{Cr}, \mathrm{Ni}, \mathrm{V})$ and silicic-alkalic compositions (Be). The main weight of variable negative values for the factor 2 produce heavy REE (from Dy to Lu), Y, and lithophile elements (Cs, $\mathrm{Rb}, \mathrm{Th}$ ). The intermediate position is occupied by $\mathrm{Gd}, \mathrm{Pb}, \mathrm{U}, \mathrm{Ga}, \mathrm{Sb}, \mathrm{W}$, and other elements. From the factor analysis results, samples of the Wudalianchi peloids are divided into 4 groups: 1 ) the main that comprises most of samples analyzed, 2) the one showing increasing $\mathrm{La} / \mathrm{Yb}$ and HFSE concentrations, 3) the one demon- strating reduced contents of $\mathrm{V}, \mathrm{Cr}, \mathrm{Ni}$, and HFSE, and 4) the one revealing high $\mathrm{Mn}$, Co and $\mathrm{Ni}$ contents (Fig. 1, a). The data points of the group 1 are distributed around the center of coordinates. Those of the group 2 are shifted from the coordinate center with increasing factors 1 and 2 towards the composition of modern soil (sample 1). The data points of the group 3 are displaced with a relative decreasing factor 1 . Those of the group 4 are located within the main group field with the positive factor 1 values.

In the trace-element grouping of peloids, the ratios of light to medium and heavy REE are of primary importance. In Fig. 2, the normalized REE peloid patterns 


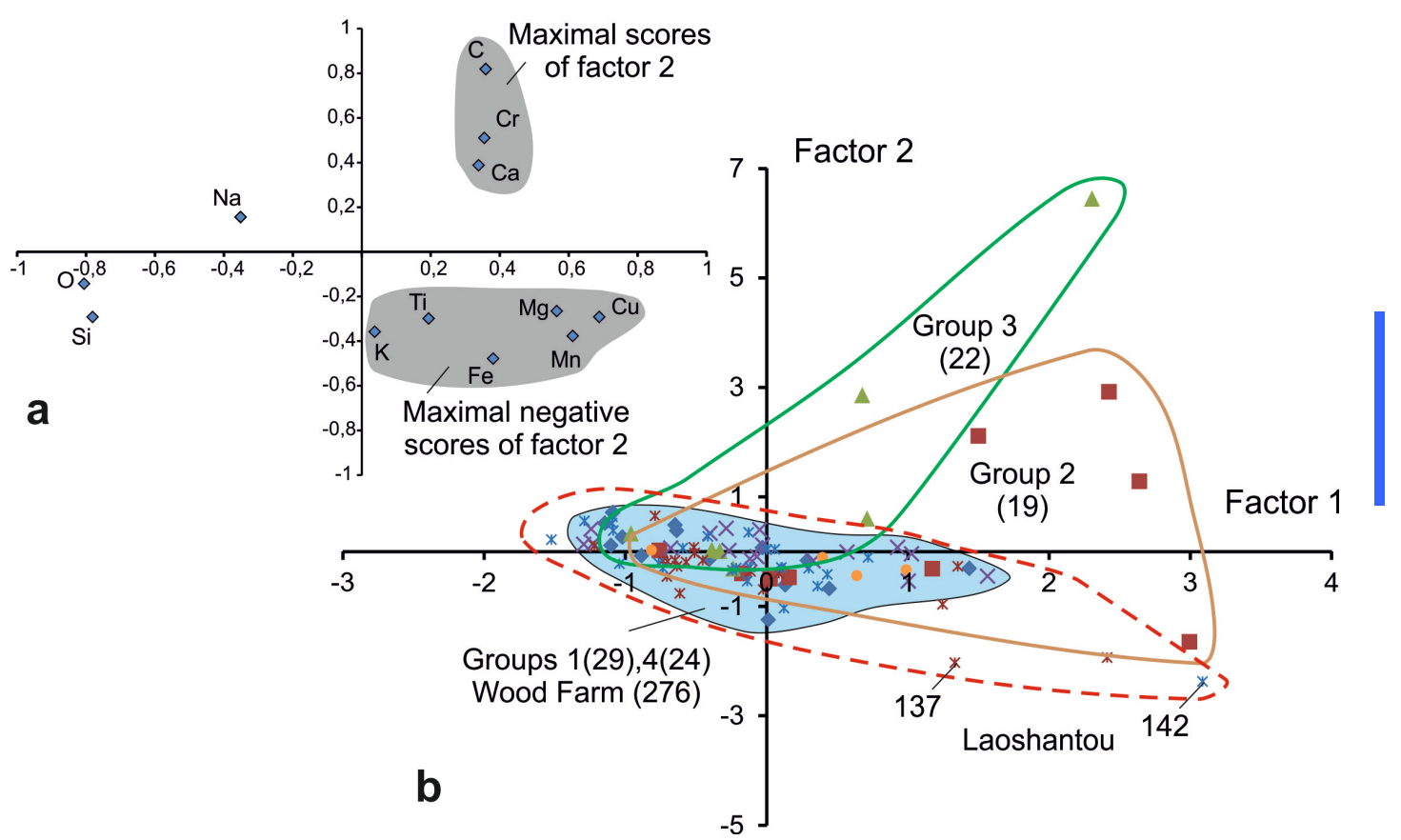

Fig. 3. Grouping of variables $(a)$ and samples $(b)$ in diagrams of factors 1 and 2 for peloids and pre-volcanic clays from Wudalianchi.

yield, however, a narrow range of compositions. All spectra clearly show Eu-minima. The line of modern soil (sample 1) that demonstrates elevated concentrations of light and reduced heavy REE dissects all peloid samples. The soil reveals no Eu anomaly. The spectra of group 4 (samples 24, 30) correspond to the middle portion of all peloid spectra and differ only by the $\mathrm{Ce}$ maximum.

The found peloid grouping in terms of relation between light-medium and heavy REE reflects the net effect of elements that correlate with light-middle and heavy members of rare-earth series, respectively. Trace-element contents in the groups vary both due to variations of $\mathrm{La} / \mathrm{Yb}$ ratio and belonging to the group of variables of light-medium or heavy REE. The elevated $\mathrm{Mn}, \mathrm{Co}$, and $\mathrm{Ni}$ concentrations in samples of group 4 might indicate technogenic contamination of the main group peloids.

The REE spectra of the gray clay from the lower part of the Laoshantou section (samples 139, 142) are at the axial part of the all peloids band. Those of the overlying red-colored sediments differs. In the dark-brown clay (sample 144), the light and middle parts of the spectrum are similar to the one of gray clay. The heavy part of the spectrum rises above the band of all-peloid spectra. The spectra of brick-red clay occur below the allpeloid spectra and intersect the latter in the heavy part of the series (Fig. 2,a).

An even greater difference in terms of REE spectra is observed between the peloids and pre-volcanic clays from the Wood Farm section. The stratum, exposed to $10 \mathrm{~m}$ depth, shows sub-horizontal fracture zones $(2 \mathrm{~cm}$, $3 \mathrm{~cm}$, and $10 \mathrm{~cm}$ ) that let water penetration. The material of the fissured layers differs from the host gray, uniform, massive argillites through ocher-color and plasticity of the material.

The uniform argillite from the upper part of the outcrop (sample 272) is characterized by a general decrease of REE content relative to the peloid band. Each of the three fractured layers shows individual rareearth spectrum. The one of the lower layer (layer 1 , sample 275) is similar to the spectrum of the darkbrown clay from the Laoshantou section (sample 144) (Fig. 2, $a, b$ ). The spectrum of the middle layer (layer 2, sample 274) is below the spectrum of the primary uniform argillite (sample 272). The uppermost 10-cm thick layer shows local crystallization of white mineral - alunogen?. Sample 271a, which is most enriched by these mineralization, demonstrates the lowest REE content. Sample 273, taken from the same part of the interlayer, which contains rare visible alunogen crystals, has a REE pattern shifted towards the Wudalianchi peloid band. Sample 273, taken in a distance over $10 \mathrm{~m}$ from samples 271, 271a, shows no alunogen. In hand specimen, yellow-ocher clay of this sample looks similar to clays from layers 1 and 2. The REE pattern of the sample is between those of samples 271 and 271a.

Comparison of minerals. To study clay minerals under the scanning electron microscope, representative samples were selected from each group of peloids: 29 (group 1), 19 (group 2), 22 (group 3), and 24 (group 4). For comparisons, clay samples 137 and 142 from Laoshantou and clay samples 276, 273, and 271 from Forest Farm were also involved in mineralogical work. Each phase was identified by concentration measurements for twelve elements. The obtained elemental matrix of the samples was processed using the factor analysis procedure. The results are shown in Fig. 3. 

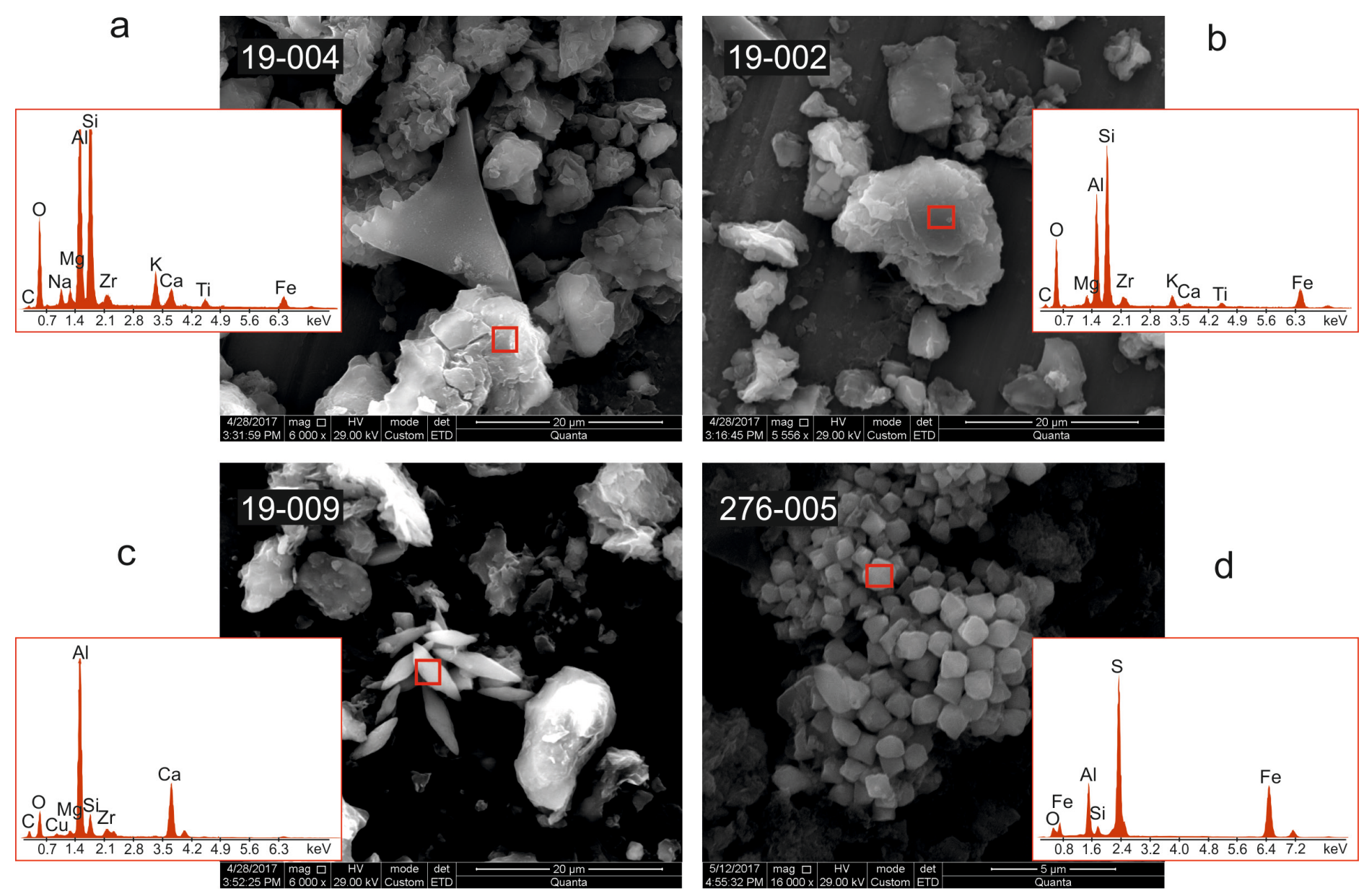

Fig. 4. Mineral phases of peloids: $a$ - Na-containing, $b$-Na-free, $c$ - aragonite, $d$ - pyrite. The Al peak is due to the composition of the sample stand.

In the coordinates of factors 1 and 2, the data points of mineral phases from peloid groups 1 and 4 fall into a single field, along which a data field of the Laoshantou clay minerals extends towards the diagram portion of positive factor 1 and negative factor 2 values. Data fields of mineral phases from peloid groups 2 and 3 yield a fan that opens towards the diagram portion of positive values both factors 1 and 2 .

The bulk of the Wood Farm clays differs from other Wudalianchi sediments by the occurrence of finegrained pyrite aggregates (Fig. 4, d) that are not visible in a hand specimen. The sulfur content in these clays reaches $4 \mathrm{wt}$. \%. Water leaking through cracks results in sulfide and sulfate mineralization: marcasite $\left(\mathrm{FeS}_{2}\right)$, gypsum $\left(\mathrm{CaSO}_{4} \cdot 2 \mathrm{H}_{2} \mathrm{O}\right)$, and alunogen $\left(\mathrm{Al}_{2}\left(\mathrm{SO}_{4}\right)_{3} \cdot 17 \mathrm{H}_{2} \mathrm{O}\right)$. In the factor diagrams of Fig. 3, the results of element measurements for sulfides and sulfates were excluded. The remaining data points of the fine mineral fraction from the Forest Farm clay fall within the field of prevailing peloids and pre-volcanic clays from Wudalianchi. Consequently, similar to groups 2 and 3 peloids and Laoshantou clays, the Forest Farm clays show an individual (sulfide-sulfate) trend, starting from the field of prevailing mineral compositions of all-clay sediments in the area.

The positive scores for factor 1 variables (see Fig. 3, b) involve $\mathrm{Cu}, \mathrm{Mn}, \mathrm{Mg}, \mathrm{C}, \mathrm{Ca}, \mathrm{Cr}, \mathrm{Fe}, \mathrm{Ti}$, and $\mathrm{K}$, the negative scores include $\mathrm{Si}, \mathrm{O}$, and $\mathrm{Na}$. The trend of prevailing mineral compositions from all-clay sediments denotes negative correlation between $\mathrm{Na}$ (Fig. 4, a) and group $\mathrm{Cu}, \mathrm{Mn}, \mathrm{Mg}, \mathrm{Fe}, \mathrm{Ti}$, and $\mathrm{K}$ (Fig. $4, b$ ). The role of the latter group increases in the Laoshantou pelitic fraction. The fan distribution of data points for minerals from groups 2 and 3 samples is due to the negative correlation between $\mathrm{Si}$, $\mathrm{O}$ group and $\mathrm{C}, \mathrm{Ca}, \mathrm{Cr}$ group (Fig. 4, c).

Concluding remarks. Volcanic rocks from Wudalianchi are characterized by high $\mathrm{K}_{2} \mathrm{O} / \mathrm{Na}_{2} \mathrm{O}$ ratios, potassium and other incompatible trace element contents, including REE [Zhang et al., 1995; Chu et al., 2013; Rasskazov et al., 2016]. Sulphides are not typical for the volcanic rocks. Peloids from Wudalianchi differ from pre-volcanic clays of the area by elevated REE concentrations and the lack of sulfide mineralization. Unlike peloids, the pre-volcanic Forest Farm sediments show lower REE concentrations and sulfide-sulfate mineralization. These sediments originated as paleopeloids that 
are compositionally comparable to the common present-day silt sulfide-type peloids. The revealed difference between peloids and pre-volcanic clays highlights the unique character of the Wudalianchi synvolcanic sedimentation.

The subdivision of the Wudalianchi peloids into 4 groups, obtained from relations between light-medium versus heavy REE and correlated trace elements, is confirmed by variations mineral compositions in pelitic fractions. The studied healing mud and pre-volcanic clays show the general mineral trend, denoted by a negative correlation in the clay particles between $\mathrm{Na}$ and other elements $(\mathrm{Cu}, \mathrm{Mn}, \mathrm{Mg}, \mathrm{Fe}, \mathrm{Ti}$, and $\mathrm{K})$. In the pelitic fraction of the Laoshantou sub-basalt clays, the role of the latter elements increases. The pelitic fraction of groups 1 and 4 exhibits the basic matrix of peloids and pre-volcanic clays, whereas the pelitic fractions of groups 2 and 3 contain phases rich in carbon and calcium, depleted in silica and oxygen. Perhaps, the peloids of groups 2 and 3 are more mature (relative to the peloids of groups 1 and 4) or have experienced superimposed processes.

Acknowledgments. This work was done in the Chinese-Russian Wudalianchi-Baikal Research Center on volcanism and environment (Scientific Research Fund of the Heilongjiang Academy of Sciences, 2017).

\section{REFERENCES}

Bokuchava N., 2009. Healing Mud of Georgia. Publishing house "Technical University", Tbilisi, 157 p. (in Russian).

Chu Z.-Y., Harvey J., Liu C.-Z., Guo J.-H., Wu F.-Y., Tian W., Zhang Y.-L., Yang Y.-H., 2013. Source of highly potassic basalts in northeast China: evidence from Re-Os, Sr-Nd-Hf isotopes and PGE geochemistry. Chemical Geology 357, 52-66. https://doi.org/10.1016/j.chemgeo.2013.08.007.

McDonough W.F., Sun S.-S., 1995. The composition of the Earth. Chemical Geology 120 (3-4), 223-253. https://doi.org/ 10.1016/0009-2541(94)00140-4.

Rasskazov S.V., Chuvashova I.S., Sun Y., Yang C., Xie Z., Yasnygina T.A., Saranina E.V., Fang Z., 2016. Sources of Quaternary potassic volcanic rocks from Wudalianchi, China: Control by transtension at the lithosphere-asthenosphere boundary layer. Geodynamics \& Tectonophysics 7 (4), 495-532. https://doi.org/10.5800/GT-2016-7-4-0223.

Stupnikova N.A., Muradov S.V., 2005. Physicochemical and microbiological studies of healing mud in the Lake Utinoye of the Kamchatka region. Bulletin of the Far East Branch of the Russian Academy of Sciences (3), 76-82 (in Russian).

Zhang M., Suddaby P., Thompson R.N., Thirlwall M.F., Menzies M.A., 1995. Potassic rocks in NE China: geochemical constraints on mantle source and magma genesis. Journal of Petrology 36 (5), 1275-1303. https://doi.org/10.1093/ petrology/36.5.1275. 